\title{
The pathological role of vascular aging in cardio-metabolic disorder
}

\author{
Goro Katsuumi ${ }^{1 \dagger}$, Ippei Shimizu ${ }^{1,2^{*}+}$, Yohko Yoshida ${ }^{1,2}$ and Tohru Minamino ${ }^{1 *}$
}

\begin{abstract}
Chronological aging is linked to cellular senescence, and there is accumulating evidence for a pathological role of cellular senescence in age-related disorders such as obesity, diabetes, and heart failure. The protein p53 has a central role in cellular senescence, and p53 expression in cardiomyocytes, vascular endothelial cells, adipocytes, and immune cells leads to the development of heart failure and diabetes. It is widely accepted that formation of capillary networks is critical for morphogenesis of organs and maintenance of homeostasis. Capillary rarefaction and hypoxia promote pathological changes in the myocardium of the failing heart, causing systolic dysfunction. Capillary rarefaction and hypoxia also cause dysfunction of brown adipose tissue (BAT), leading to systemic metabolic disorders with promotion of diabetes. Vascular endothelial cell senescence develops in heart failure and diabetes and is responsible for progression of these age-related disorders. In a murine model of left ventricular pressure overload, increased expression of p53 in vascular endothelial cells and bone marrow cells promotes inflammatory cell infiltration into the heart, contributing to cardiac remodeling and systolic dysfunction. Metabolic stress up-regulates p53 expression in endothelial cells, while reducing the phosphorylation of endothelial nitric oxide synthase (eNOS) and glucose transporter (GLUT)1 expression in these cells. These changes lead to suppression of mitochondrial biogenesis and glucose uptake in the skeletal muscle and promote the development of systemic metabolic dysfunction. Suppression of vascular aging and vascular dysfunction is critically important for maintenance of organ homeostasis and is essential for prevention or treatment of heart failure, obesity, and diabetes.
\end{abstract}

Keywords: p53, Cellular senescence, Endothelial cell, Heart failure, Diabetes

\section{Background}

Chronological aging increases the risk of age-related disorders such as obesity, diabetes, and heart failure. Aging also occurs at the cellular level. Shortening of telomeres associated with cell division triggers the DNA damage response and cellular senescence, which is known as replicative senescence and is mainly mediated via a p53 signaling pathway $[10,12]$. In addition, stress due to factors such as cytokines and reactive oxygen species also leads to p53-mediated cellular senescence that is termed premature senescence [27]. Senescent cells are characterized by growth arrest associated with various alterations of gene expression [10, 24, 32, 37].

\footnotetext{
*Correspondence: ippeishimizu@yahoo.co.jp; t_minamino@yahoo.co.jp ${ }^{\dagger}$ Equal contributors

'Department of Cardiovascular Biology and Medicine, Niigata University Graduate School of Medical and Dental Sciences, 1-757 Asahimachidori, Chuo-ku, Niigata 951-8510, Japan

Full list of author information is available at the end of the article
}

Obesity and its associated disorders are among the top health problems in many societies. Obesity promotes pathological processes that contribute to atherosclerotic disease, heart failure, and diabetes, and there is evidence for a causal role of cellular senescence in these diseases. Metabolic stress leads to p53-induced cellular senescence in adipocytes, resulting in adipose tissue inflammation and systemic metabolic dysfunction [16]. Obesity has also been linked to elevated p53 expression in vascular endothelial cells, which reduces the activation of endothelial nitric oxide synthase (eNOS) and glucose transporter (GLUT)1 in these cells and contributes to suppression of mitochondrial biogenesis and glucose uptake in the skeletal muscle, leading to systemic metabolic dysfunction [41]. In addition, capillary rarefaction and hypoxia cause dysfunction of brown adipose tissue (BAT) and promote systemic metabolic abnormalities [28]. Recently, vascular senescence was shown to have a 
pathological role in the progression of heart failure. In a murine model of left ventricular pressure overload, increased adrenergic signaling associated with heart failure was found to up-regulate p53 expression in both endothelial cells and bone marrow cells, contributing to cardiac inflammation and remodeling [42]. Heart failure also promotes p53-induced adipocyte senescence and visceral fat inflammation, leading to the development of systemic insulin resistance and hyperinsulinemia. In turn, hyperinsulinemia contributes to cardiac hypertrophy via the Akt signaling pathway, possibly because cardiac tissue is slow to develop insulin resistance, and activation of this pathway has a detrimental effect on cardiac homeostasis by promoting pathological cardiomyocyte hypertrophy, cardiomyocyte/capillary mismatch, and hypoxia [29].

It is widely accepted that formation of vascular networks is critically important for organ morphogenesis and for maintenance of homeostasis, while cellular senescence has a pathological role in promoting vascular dysfunction that leads to organ dysfunction and systemic metabolic disorders $[6,28,41,42]$. In this review, we discuss the role of vascular aging in cardio-metabolic disorders.

\section{Pathological role of vascular aging/dysfunction in heart failure}

The prognosis of severe heart failure is still very poor, and it is urgent to find new therapeutic targets for this disorder [2]. Hypertensive heart disease is among the chief causes of heart failure. When cardiac tissue is exposed to pressure overload, cardiac hypertrophy occurs in step with angiogenesis as an adaptive response to maintain systolic function. Sustained pressure overload promotes the transition to decompensated heart failure, which features excessive cardiomyocyte hypertrophy uncoordinated with the angiogenic response [33]. The resulting capillary rarefaction and hypoxia contribute to cardiac remodeling and systolic dysfunction. It was reported that increased cardiac expression of p53, which induces cellular senescence, promotes cardiac dysfunction in a murine model of pressure overload. In addition, p53 suppresses cardiac angiogenesis via inhibition of hypoxia-inducible factor $1 \alpha$ (Hif- $1 \alpha)$ and vascular endothelial growth factor (VEGF), thus promoting cardiac hypoxia and remodeling [25]. It is well accepted that sterile inflammation contributes to the progression of cardiac remodeling associated with heart failure, but the mechanistic link between p53 and inflammation in the failing heart has been unclear [7]. Recently, activation of p53 signaling in vascular endothelial cells and bone marrow cells was reported to be the underlying cause of cardiac inflammation in a murine model of left ventricular (LV) pressure overload [42]. In this model, p53 expression was significantly increased in cardiac microvascular endothelial cells and bone marrow cells, leading to upregulation of intercellular adhesion molecule (ICAM)-1 expression by endothelial cells and an increase of integrin alpha-L in macrophages. Genetic deletion of p53 in endothelial cells or bone marrow cells reduced the expression of these adhesion molecules, suppressed inflammatory cell infiltration into cardiac tissue, inhibited production of pro-inflammatory cytokines, and ameliorated cardiac dysfunction due to LV pressure overload. Conversely, forced expression of p53 in bone marrow cells led to exacerbation of cardiac inflammation and systolic dysfunction. It is well known that activation of the sympathetic nervous system (SNS) occurs in heart failure patients and is associated with a poor prognosis [3]. In the LV pressure overload model, norepinephrine markedly increased the level of reactive oxygen species (ROS) and p53 expression in macrophages and endothelial cells, while inhibition of adrenergic signaling through suppression of beta- 2 adrenergic receptor expression in endothelial cells or bone marrow cells decreased ROS and p53 levels, and also ameliorated cardiac inflammation and systolic dysfunction due to pressure overload. These results suggest that activation of SNS/ROS/p53 signaling promotes interaction between endothelial cells and bone marrow-derived inflammatory cells via upregulation of ICAM-1 and integrin expression, resulting in exacerbation of cardiac dysfunction [42] (Fig. 1). It was also reported that increased p53 signaling in endothelial cells led to capillary rarefaction in cardiac tissue in a murine model of LV pressure overload, while depletion of endothelial cell p53 ameliorated capillary rarefaction, improved cardiac function, and suppressed cardiac fibrosis/remodeling [8]. Cardiac expression of p53 is upregulated by LV pressure overload, but this change is significantly suppressed by endothelial cell p53 depletion. These results indicate that infiltration of inflammatory cells into cardiac tissue (promoted by endothelial cell senescence) is the initial step in the process of cardiac remodeling due to LV pressure overload, and this process is accelerated by capillary rarefaction and hypoxia $[8,25,42]$. It is well accepted that the non-selective $\beta$-blocker, carvedilol, has a cardioprotective effect contributing for the better clinical outcomes in severe heart failure patients with reduced ejection fraction. Carvedilol is known to bind preferentially to beta- 2 adrenergic receptor, and it may exert its biological effects via the suppression of SNS/ROS/p53 signaling mediated via beta-2 adrenergic receptor in endothelial cells. Accordingly, suppression of endothelial cell senescence could be a new therapeutic target for heart failure associated with reduced cardiac systolic function.

It is well known that approximately half of the heart failure is classified as heart failure with preserved ejection fraction (HFpEF). HFpEF is known to be predominant 


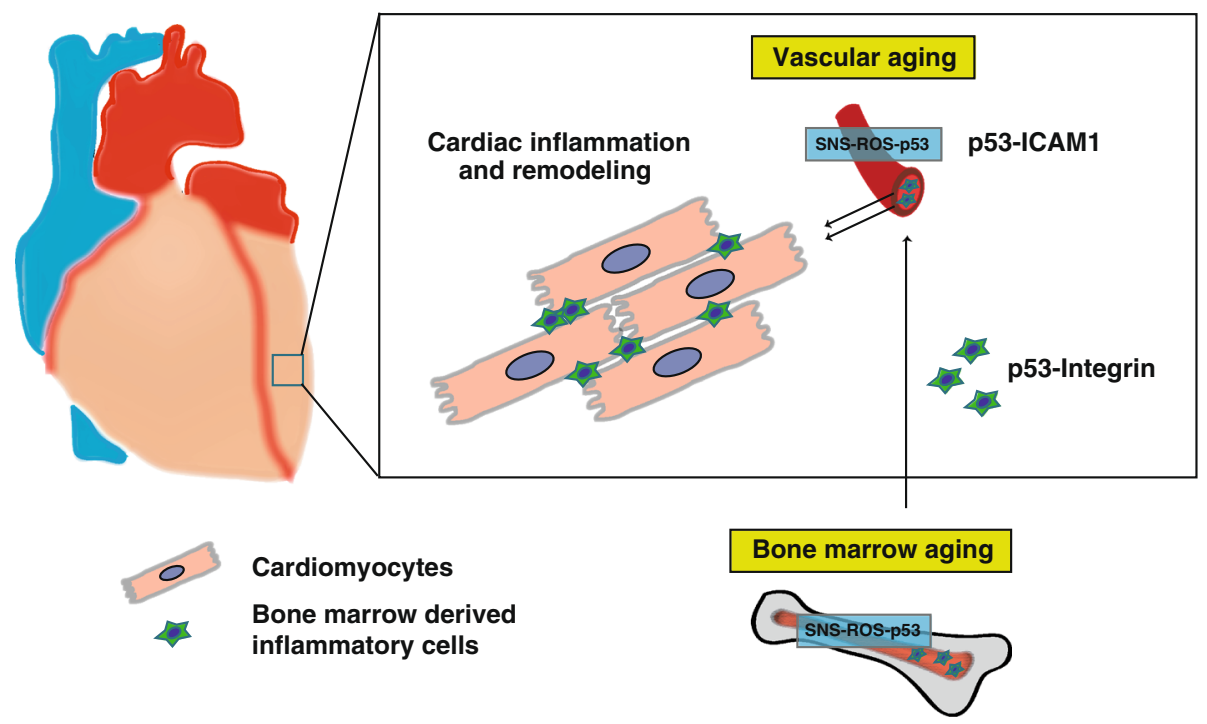

Fig. 1 The role of vascular and bone marrow aging in heart failure. Activation of sympathetic nervous system (SNS)/ROS/p53 signaling promotes the interaction between endothelial cells and bone marrow-derived inflammatory cells by the up-regulation of ICAM-1 and integrin expression to exacerbate cardiac dysfunction

among elderly individuals. Overweight/obesity, hypertension, and diabetes mellitus are also known to become the risk factors for promoting this pathological condition. Cardiomyocyte hypertrophy and interstitial fibrosis, associated with incomplete relaxation of myocardial strips and cardiomyocyte stiffness, develop in $\operatorname{HFpEF}[13,26,38]$. Recently, coronary microvascular inflammation is thought crucial for the development of HFpEF [22]. Considering that cellular senescence has a central role in inducing vascular dysfunction, it is highly possible that this would promote pathologies in HFpEF. Further studies are needed to analyze the role of vascular aging in this critical disorder.

\section{Pathological role of vascular aging/dysfunction in obesity}

Skeletal muscle

The skeletal muscle makes a major contribution to glucose disposal, so maintenance of skeletal muscle homeostasis is crucial for metabolic health. Metabolic stress induces accumulation of lipids and causes inflammation that promotes insulin resistance in the skeletal muscle, contributing to the development of systemic insulin resistance $[15,23]$. Capillaries have an important role in the regulation of skeletal muscle metabolism. An increase of p53 in the vascular endothelium was reported in a murine model of dietary obesity [41]. In this model, genetic depletion of endothelial p53 reduced the accumulation of visceral and subcutaneous fat and led to improvement of systemic insulin resistance. eNOS upregulates peroxisome proliferator-activated receptor- $\gamma$ coactivator- $1 \alpha$ (PGC1- $\alpha$ ) in the skeletal muscle, while p53 suppresses the activation of eNOS. It was found that the depletion of endothelial cell p53 promoted glucose uptake by the skeletal muscle via up-regulation of GLUT1 expression in endothelial cells. These findings suggest that suppression of vascular aging contributes to better metabolic health by promoting mitochondrial biogenesis in the skeletal muscle [41] (Fig. 2).

\section{Brown adipose tissue}

Several types of fat exist in the body, including white, brown, and beige adipose tissue. BAT was initially characterized as a thermogenic organ that is abundantly expressed in newborn infants and small rodents, but subsequent studies have shown that adult humans also have BAT [4]. In addition to its role in thermogenesis, BAT is now known to make a large contribution to the regulation of systemic metabolism $[1,18,34]$. In adults, BAT activity was found to decline with obesity and aging, but the detailed mechanisms involved were uncertain. BAT is highly vascular, and metabolic stress was recently shown to suppress angiogenesis by reducing the expression of vascular endothelial growth factor-A (VEGF-A), a major pro-angiogenic molecule, in brown adipocytes due to accumulation of fatty acids. This leads to capillary rarefaction and hypoxia, which affect BAT much more prominently than white adipose tissue (WAT), leading to "whitening" of BAT that is associated with diminished $\beta$-adrenergic signaling, accumulation of large lipid droplets, and mitochondrial dysfunction or loss. These changes of the BAT microenvironment impair thermogenesis and promote systemic metabolic dysfunction. Whitening of BAT has also been observed after ablation of Vegfa in the adipose tissue of non-obese 


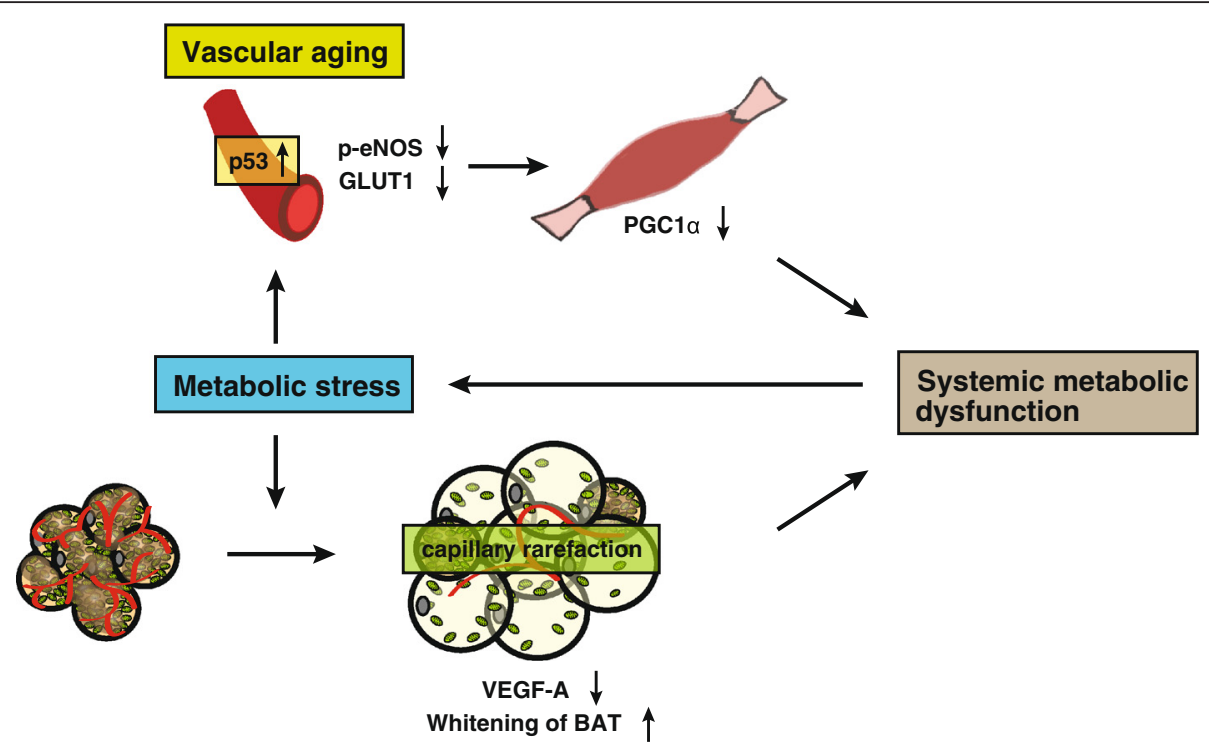

Fig. 2 The role of vascular aging and hypoxia-induced BAT dysfunction in obesity. Metabolic stress up-regulates p53 in endothelial cells and reduces the activation of eNOS and GLUT1 level. This leads to reduced PGC1-a expression in skeletal muscle leading to the development of systemic metabolic dysfunction. In brown adipose tissue (BAT), metabolic stress promotes capillary rarefaction by the suppression of VEGF-A, and this leads to the whitening of BAT

mice, which demonstrated impairment of systemic glucose metabolism and reduction of thermogenesis. Importantly, specific introduction of Vegfa into the BAT of mice with dietary obesity restored its vascularity and ameliorated brown adipocyte dysfunction, and this rebrowning of BAT was associated with improvement of insulin sensitivity. These data indicate that overnutrition promotes hypoxia in BAT, causing it to whiten through mitochondrial dysfunction and loss, and subsequently contributing to impaired systemic glucose metabolism [28] (Fig. 2). Recently, the expression of an antiangiogenic VEGF-A splice isoform (VEGF-A165b) was shown to increase upon metabolic stress and inhibit vascularization in ischemic hind limbs [14]. The role of VEGF-A165b in the maintenance of BAT homeostasis remains an open question.

\section{White adipose tissue}

WAT was initially thought to be mainly involved in energy storage, but it is now well known to be an active endocrine organ secreting humoral mediators called "adipokines" [20]. Metabolic stress induces the influx of fatty acids into white adipocytes, leading to increased production of inflammatory cytokines and promoting systemic metabolic dysfunction. Angiogenic factors have been reported to have a critical role in the maintenance of homeostasis in WAT [5, 35, 36]. In obese patients and obese mice, WAT displays capillary rarefaction and hypoxia associated with the infiltration of macrophages and increased production of pro-inflammatory cytokines. In obesity, the VEGF-A level has variously been reported to be increased $[11,40]$, decreased $[9,17,21]$, or unchanged [39], but there is a consensus that inadequate angiogenesis occurs during WAT expansion associated with metabolic stress. Disruption of VEGF expression in the fat cells of mice leads to capillary rarefaction and hypoxia in visceral WAT along with increased Tnf expression, and the mice develop systemic metabolic dysfunction when fed a high-calorie diet. In contrast, forced VEGF expression in fat cells increases the vascularity of adipose tissue and ameliorates systemic metabolic dysfunction in mice with dietary obesity. These findings indicate that capillary network formation has a crucial role in WAT homeostasis and metabolic health $[5,35,36]$.

Recently, impaired angiogenesis in visceral adipose tissue was reported to associate with high VEGF-A165b expression in the fat, suggesting that the inhibition of VEGF-A165b would have a therapeutic potential to maintain homeostasis in visceral fat, contributing to the suppression of systemic metabolic dysfunction [19].

In both white and brown adipose tissue, molecules or mechanisms contributing to the up-regulation of angiogenic VEGF are yet to be defined. Studies indicate that hypoxia-inducible factor $1 \alpha$ (HIF $1 \alpha)$ in the visceral fat is increased in response to obesity. In cardiac tissue and other organs, HIF $1 \alpha$ is well accepted as a critical regulator for angiogenesis [25]. Interestingly, in both fats, HIF1 $\alpha$ does not induce angiogenesis; instead, it activates fibrotic response or autophagy and disturbs homeostasis in these organs $[9,28]$. Further studies are needed to explore mechanisms that would promote angiogenesis in white and brown adipose tissue. 


\section{Conclusions}

Capillaries are critically involved in maintenance of homeostasis in the heart, BAT and WAT, and skeletal muscle [5, 25, 28, 35, 36, 41, 42]. Studies have shown that endothelial cell senescence leads to cardiac inflammation, capillary rarefaction, and hypoxia, thereby promoting pathologic cardiac remodeling in response to LV pressure overload [25, 42]. In a murine model of LV pressure overload, the downregulation of endothelial cell expression of p53 (a critical regulator of cellular senescence) has been shown to inhibit cardiac inflammation, promote angiogenesis, and protect cardiac function [42]. Studies performed in murine models of obesity have shown that capillary rarefaction also develops in BAT as a response to metabolic stress. Accumulation of lipids leads to the suppression of VEGF-A, a critical regulator of angiogenesis, and induces capillary rarefaction and hypoxia, promoting the whitening of brown fat and systemic metabolic dysfunction. Conversely, up-regulation of Vegfa expression promotes the re-browning of whitened BAT and improves systemic metabolic health [28]. Endothelial cell senescence is linked with metabolic dysfunction in skeletal muscle via suppression of mitochondrial biogenesis and contributes to systemic metabolic dysfunction [41]. These results provide evidence that maintenance of vascular homeostasis through regulation of endothelial cell senescence is critically important for suppressing pathologic changes associated with heart failure, obesity, and diabetes. It has been reported that systemic insulin resistance develops during heart failure in humans and mice. Excessive lipolysis in visceral fat promotes adipose tissue inflammation during LV pressure overload and leads to systemic insulin resistance with hyperinsulinemia [30], while excessive insulin signaling has been reported to induce pathological cardiac hypertrophy associated with capillary rarefaction and hypoxia [29]. Studies have shown that p53-induced senescence of adipocytes causes the development of adipose tissue inflammation and systemic insulin resistance in animal models of obesity or heart failure, contributing to the progression of these age-related disorders [16, 30, 31]. Recent studies have also indicated that endothelial cell senescence has a pathological role in systemic insulin resistance through impairment of skeletal muscle metabolism [41]. Thus, maintenance of vascular homeostasis is essential in the management of obesity, diabetes, and heart failure.

\section{Acknowledgements}

This work was supported by a Grant-in-Aid for Scientific Research, a Grant-inAid for Scientific Research on Innovative Areas (Stem Cell Aging and Disease), and a Grant-in-Aid for Exploratory Research from the Ministry of Education, Culture, Sports, Science and Technology (MEXT) of Japan and grants from the Ono Medical Research Foundation, the Japan Diabetes Foundation, the Takeda Science Foundation, and the Takeda Medical Research Foundation (to TM) as well as by a Grants-in-Aid for Young Scientists (Start-up) (JSPS
KAKENHI Grant Number 26893080), and grants from the Uehara Memorial Foundation, Takeda Science Foundation, Kowa Life Science Foundation, Manpei Suzuki Diabetes Foundation, Kanae Foundation, Japan Heart Foundation Research Grant, Senri Life Science Foundation, SENSHIN Medical Research Foundation, ONO Medical Research Foundation, Tsukada Grant for Niigata University Medical Research, The Nakajima Foundation, Suzuken Memorial Foundation, HOKUTO Corporation, Inamori Foundation, Mochida Memorial Foundation for Medical \& Pharmaceutical Research, Banyu Foundation Research Grant, and Grant for Basic Science Research Projects from The Sumitomo Foundation (to IS) and by a Grant-in-Aid for Young Scientists from MEXT, a Japan Heart Foundation Dr. Hiroshi Irisawa \& Dr. Aya Irisawa Memorial Research Grant, Senshin Medical Research Foundation grant, Suzuken memorial foundation, Takeda Science Foundation, ONO Medical Research Foundation, Uehara Memorial Foundation, and Research Foundation for Community Medicine (to YY) and by a grant from Bourbon (to TM, IS, and YY).

\section{Authors' contributions}

GK, IS, YY, and TM wrote the paper. IS and TM supervised the manuscript preparation. All authors read and approved the final manuscript.

\section{Competing interests}

The authors declare that they have no competing interests.

\section{Author details}

${ }^{1}$ Department of Cardiovascular Biology and Medicine, Niigata University Graduate School of Medical and Dental Sciences, 1-757 Asahimachidori, Chuo-ku, Niigata 951-8510, Japan. ²Division of Molecular Aging and Cell Biology, Niigata University Graduate School of Medical and Dental Sciences, 1-757 Asahimachidori, Chuo-ku, Niigata 951-8510, Japan.

Received: 9 March 2016 Accepted: 22 June 2016

Published online: 16 August 2016

\section{References}

1. Bartelt A, Bruns OT, Reimer R, Hohenberg H, Ittrich H, Peldschus K, Kaul M.G, Tromsdorf, UI, Weller, H, Waurisch, C et al. Brown adipose tissue activity controls triglyceride clearance. Nat Med. 2010;17:200-5.

2. Braunwald E. The war against heart failure: the Lancet lecture. Lancet. 2015; 385:812-24

3. Cohn JN, Levine TB, Olivari MT, Garberg V, Lura D, Francis GS, Simon AB, Rector T. Plasma norepinephrine as a guide to prognosis in patients with chronic congestive heart failure. N Engl J Med. 1984;311:819-23.

4. Cypess AM, Lehman S, Williams G, Tal I, Rodman D, Goldfine AB, Kuo, FC, Palmer, E.L, Tseng, YH, Doria, A et al. Identification and importance of brown adipose tissue in adult humans. N Engl J Med. 2009;360:1509-17.

5. Elias I, Franckhauser S, Ferre T, Vila L, Tafuro S, Munoz S, Roca C, Ramos D, Pujol A, Riu E et al. Adipose tissue overexpression of vascular endothelial growth factor protects against diet-induced obesity and insulin resistance. Diabetes. 2012;61:1801-13.

6. Ferrara N. Vascular endothelial growth factor: basic science and clinical progress. Endocr Rev. 2004;25:581-611.

7. Frieler RA, Mortensen RM. Immune cell and other noncardiomyocyte regulation of cardiac hypertrophy and remodeling. Circulation. 2015;131: 1019-30.

8. Gogiraju R, Xu X, Bochenek ML, Steinbrecher JH, Lehnart SE, Wenzel P, Kessel M, Zeisberg E.M, Dobbelstein, M, Schafer K. Endothelial p53 deletion improves angiogenesis and prevents cardiac fibrosis and heart failure induced by pressure overload in mice. J Am Heart Assoc. 2015;4:e001770.

9. Halberg N, Khan T, Trujillo ME, Wernstedt-Asterholm I, Attie AD, Sherwani S, Wang ZV, Landskroner-Eiger S, Dineen S, Magalang UJ et al. Hypoxia-inducible factor 1alpha induces fibrosis and insulin resistance in white adipose tissue. Mol Cell Biol. 2009;29:4467-83.

10. Hayflick L, Moorhead PS. The serial cultivation of human diploid cell strains. Exp Cell Res. 1961;25:585-621.

11. He Q, Gao Z, Yin J, Zhang J, Yun Z, Ye J. Regulation of HIF-1\{alpha\} activity in adipose tissue by obesity-associated factors: adipogenesis, insulin, and hypoxia. Am J Physiol Endocrinol Metab. 2011;300:E877-885.

12. Jaskelioff $M$, Muller FL, Paik JH, Thomas E, Jiang S, Adams AC, Sahin E, Kost-Alimova M, Protopopov A, Cadinanos J et al. Telomerase reactivation reverses tissue degeneration in aged telomerase-deficient mice. Nature. 2011;469:102-6. 
13. Kasner M, Westermann D, Lopez B, Gaub R, Escher F, Kuhl U, Schultheiss HP, Tschope C. Diastolic tissue Doppler indexes correlate with the degree of collagen expression and cross-linking in heart failure and normal ejection fraction. J Am Coll Cardiol. 2011;57:977-85.

14. Kikuchi R, Nakamura K, MacLauchlan S, Ngo DT, Shimizu I, Fuster JJ, Katanasaka Y, Yoshida S, Qiu Y, Yamaguchi TP et al. An antiangiogenic isoform of VEGF-A contributes to impaired vascularization in peripheral artery disease. Nat Med. 2014;20:1464-71.

15. Lumeng CN, Saltiel AR. Inflammatory links between obesity and metabolic disease. J Clin Invest. 2011;121:2111-7.

16. Minamino T, Orimo M, Shimizu I, Kunieda T, Yokoyama M, Ito T, Nojima A, Nabetani A, Oike Y, Matsubara $\mathrm{H}$ et al. A crucial role for adipose tissue p53 in the regulation of insulin resistance. Nat Med. 2009;15:1082-7.

17. Miranda M, Escote X, Ceperuelo-Mallafre V, Megia A, Caubet E, Naf S, Gomez JM, Gonzalez-Clemente JM, Vicente V, Vendrell J. Relation between human LPIN1, hypoxia and endoplasmic reticulum stress genes in subcutaneous and visceral adipose tissue. Int J Obes (Lond). 2010;34:679-86.

18. Nedergaard J, Cannon B. The changed metabolic world with human brown adipose tissue: therapeutic visions. Cell Metab. 2010;11:268-72.

19. Ngo DT, Farb MG, Kikuchi R, Karki S, Tiwari S, Bigornia SJ, Bates DO, LaValley MP, Hamburg NM, Vita JA et al. Antiangiogenic actions of vascular endothelial growth factor-A165b, an inhibitory isoform of vascular endothelial growth factor-A, in human obesity. Circulation. 2014;130:1072-80.

20. Ouchi N, Parker JL, Lugus JJ, Walsh K. Adipokines in inflammation and metabolic disease. Nat Rev Immunol. 2011;11:85-97.

21. Pasarica M, Sereda OR, Redman LM, Albarado DC, Hymel DT, Roan LE, Rood JC, Burk DH, Smith SR. Reduced adipose tissue oxygenation in human obesity: evidence for rarefaction, macrophage chemotaxis, and inflammation without an angiogenic response. Diabetes. 2009;58:718-25.

22. Paulus WJ, Tschope C. A novel paradigm for heart failure with preserved ejection fraction: comorbidities drive myocardial dysfunction and remodeling through coronary microvascular endothelial inflammation. J Am Coll Cardiol. 2013;62:263-71.

23. Pillon NJ, Bilan PJ, Fink LN, Klip A. Cross-talk between skeletal muscle and immune cells: muscle-derived mediators and metabolic implications. Am J Physiol Endocrinol Metab. 2013;304:E453-465.

24. Rodier F, Coppe JP, Patil CK, Hoeijmakers WA, Munoz DP, Raza SR, Freund A, Campeau E, Davalos AR, Campisi J. Persistent DNA damage signalling triggers senescence-associated inflammatory cytokine secretion. Nat Cell Biol. 2009;11:973-9.

25. Sano M, Minamino T, Toko H, Miyauchi H, Orimo M, Qin Y, Akazawa H, Tateno K, Kayama Y, Harada M et al. p53-induced inhibition of Hif-1 causes cardiac dysfunction during pressure overload. Nature. 2007;446:444-8.

26. Selby DE, Palmer BM, LeWinter MM, Meyer M. Tachycardia-induced diastolic dysfunction and resting tone in myocardium from patients with a normal ejection fraction. J Am Coll Cardiol. 2011;58:147-54.

27. Serrano M, Lin AW, McCurrach ME, Beach D, Lowe SW. Oncogenic ras provokes premature cell senescence associated with accumulation of p53 and p16INK4a. Cell. 1997:88:593-602.

28. Shimizu, I., Aprahamian, T., Kikuchi, R., Shimizu, A., Papanicolaou, K.N., MacLauchlan, S., Maruyama, S., and Walsh, K. (2014a). Vascular rarefaction mediates whitening of brown fat in obesity. J Clin Invest 124, 2099-2112.

29. Shimizu I, Minamino T, Toko H, Okada S, Ikeda H, Yasuda N, Tateno K, Moriya J, Yokoyama M, Nojima A et al. Excessive cardiac insulin signaling exacerbates systolic dysfunction induced by pressure overload in rodents. J Clin Invest. 2010;120:1506-14.

30. Shimizu I, Yoshida Y, Katsuno T, Tateno K, Okada S, Moriya J, Yokoyama M, Nojima A, Ito T, Zechner $R$ et al. p53-induced adipose tissue inflammation is critically involved in the development of insulin resistance in heart failure. Cell Metab. 2012;15:51-64

31. Shimizu I, Yoshida Y, Moriya J, Nojima A, Uemura A, Kobayashi Y, Minamino T. Semaphorin3E-induced inflammation contributes to insulin resistance in dietary obesity. Cell Metab. 2013;18:491-504.

32. Shimizu, I., Yoshida, Y., Suda, M., and Minamino, T. (2014b). DNA damage response and metabolic disease. Cell Metab 20, 967-977.

33. Shiojima I, Sato K, Izumiya Y, Schiekofer S, Ito M, Liao R, Colucci WS, Walsh K. Disruption of coordinated cardiac hypertrophy and angiogenesis contributes to the transition to heart failure. J Clin Invest. 2005;115:2108-18.

34. Stanford Kl, Middelbeek RJ, Townsend KL, An D, Nygaard EB, Hitchcox KM, Markan KR, Nakano K, Hirshman MF, Tseng YH et al. Brown adipose tissue regulates glucose homeostasis and insulin sensitivity. J Clin Invest. 2013;123:215-23.

35. Sun K, Wernstedt Asterholm I, Kusminski CM, Bueno AC, Wang ZV, Pollard JW, Brekken RA, Scherer PE. Dichotomous effects of VEGF-A on adipose tissue dysfunction. Proc Natl Acad Sci U S A. 2012;109:5874-9.

36. Sung HK, Doh KO, Son JE, Park JG, Bae Y, Choi S, Nelson, SM, Cowling R, Nagy $\mathrm{K}$, Michael IP et al. Adipose vascular endothelial growth factor regulates metabolic homeostasis through angiogenesis. Cell Metab. 2013;17:61-72.

37. Tchkonia T, Zhu Y, van Deursen J, Campisi J, Kirkland JL. Cellular senescence and the senescent secretory phenotype: therapeutic opportunities. J Clin Invest. 2013;123:966-72.

38. van Heerebeek L, Borbely A, Niessen HW, Bronzwaer JG, van der Velden J, Stienen GJ, Linke WA, Laarman GJ, Paulus WJ. Myocardial structure and function differ in systolic and diastolic heart failure. Circulation. 2006;113: 1966-73.

39. Voros G, Maquoi E, Demeulemeester D, Clerx N, Collen D, Lijnen HR. Modulation of angiogenesis during adipose tissue development in murine models of obesity. Endocrinology. 2005;146:4545-54.

40. Ye J, Gao Z, Yin J, He Q. Hypoxia is a potential risk factor for chronic inflammation and adiponectin reduction in adipose tissue of ob/ob and dietary obese mice. Am J Physiol Endocrinol Metab. 2007;293:E1118-1128.

41. Yokoyama M, Okada S, Nakagomi A, Moriya J, Shimizu I, Nojima A, Yoshida Y, Ichimiya H, Kamimura N, Kobayashi Y et al. Inhibition of endothelial p53 improves metabolic abnormalities related to dietary obesity. Cell Rep. 2014; 7(5):1691-703.

42. Yoshida Y, Shimizu I, Katsuumi G, Jiao S, Suda M, Hayashi Y, Minamino T. p53-induced inflammation exacerbates cardiac dysfunction during pressure overload. J Mol Cell Cardiol. 2015;85:183-98.

\section{Submit your next manuscript to BioMed Central and we will help you at every step:}

- We accept pre-submission inquiries

- Our selector tool helps you to find the most relevant journal

- We provide round the clock customer support

- Convenient online submission

- Thorough peer review

- Inclusion in PubMed and all major indexing services

- Maximum visibility for your research

Submit your manuscript at www.biomedcentral.com/submit
Biomed Central 